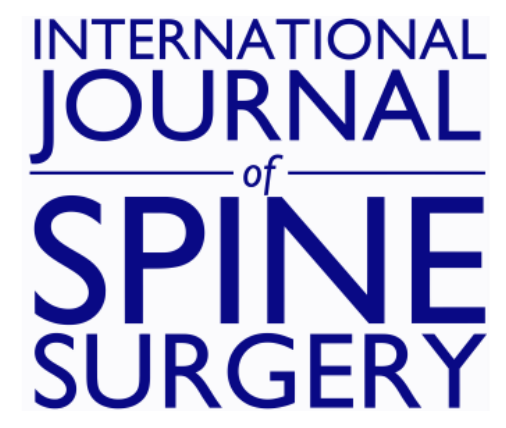

\title{
Comparison of Single-Level and Multiple-Level Outcomes of Total Disc Arthroplasty: 24-Month Results
}

Christoph Schätz, Karsten Ritter-Lang, Lutz Gössel and Nadine Dreßler

Int J Spine Surg 2015, 9 ()

doi: https://doi.org/10.14444/2014

http://ijssurgery.com/content/9/14

This information is current as of April 26, 2023.

Email Alerts Receive free email-alerts when new articles cite this article. Sign up at:

http://ijssurgery.com/alerts

The International Journal of Shing Surgerhy 2397 Waterbury Circle, Suite 1,

Aurora, IL 60504, Phone: +1-630-375-1432

(C) 2015 ISASS. All Rights Reserved. 


\section{Comparison of Single-Level and Multiple-Level Outcomes of Total Disc Arthroplasty: 24-Month Results}

Christoph Schätz, Dr. med., ${ }^{1}$ Karsten Ritter-Lang, Dr. med., ${ }^{2}$ Lutz Gössel, Dr. med., ${ }^{1}$ Nadine Dreßler, Dr. med. ${ }^{2}$

1 Orthopädische Klinik Markgröningen gGmbH, Markgröningen, Germany, 2Spezialpraxis für Wirbelsäulenchirurgie, Potsdam, Germany

\section{Abstract}

Background

Low back pain is one of the most prevalent problems in industrialized countries, affecting as many as $80 \%$ of all adults at some time in their lives. Among the significant contributors to low back pain is degenerative disc disease (DDD). Although fusion has been well accepted for treatment of DDD, high rates of complications and stress to adjacent segments remain a concern. Lumbar total disc replacement (TDR) was developed with a goal of preserving motion and avoiding various fusion-related complications, but the relative merits of single vs. multiple level arthroplasty remain unclear.

Methods

This is a multi-center, single arm, prospective post-market registry of the M6-L, consisting of consecutive patients presenting with lumbar DDD who agreed to participate. This paper reports on those patients who have completed at least 24 months of followup to date. Clinical outcome measures include the Oswestry Disability Index (ODI) and back and leg Visual Analogue Scales (VAS). Radiographic analysis of disc angle and range of motion (ROM) was also performed.

Results

Results for 83 patients comprising 121 implants in two cohorts (49 single level (SL), 34 multiple levels (ML)) are reported. Both cohorts experienced significant improvement at 24 months including significant decreases in ODI and VAS. Relative to SL procedures, ML procedures demonstrated either comparable results, or results that trended favorably towards the ML procedures. Index and global ROM at 24 months were not significantly different between the two cohorts, while the disc angles were larger in the SL cohort regardless of index level.

\section{Conclusions}

This is the first study to report clinical and radiographic outcomes of TDR with the M6-L in SL vs ML procedures with two years of followup. The results suggest initial device safety and effectiveness when used for the treatment of lumbar degenerative disc disease at one or more levels.

KEYWORDS: TOTAL DISC REPLACEMENT, LUMBAR DISC DISEASE, LOW BACK PAIN

VOLUME 9 ARTICLE 14 DOI: 10.14444/2014

\section{Introduction}

Low back pain is one of the most prevalent problems in industrialized countries, affecting as many as $80 \%$ of all adults at some time in their lives. ${ }^{1}$ It often results in decline in the quality of life of the affected individuals. Among the significant contributors to low back pain is degenerative disc disease (DDD) of the spine. Degenerative disc disease can lead to chronic low back pain and is defined by a series of events which may cause inflammation, disc dehydration and restricted mobility of the spine. ${ }^{2}$ In addition to non- operative management of the condition, patients who experience uncontrolled low back pain as a result of DDD may take advantage of numerous therapeutic techniques. Until the emergence of lumbar artificial discs, lumbar fusion surgery was considered to be the standard of care in such instances. Lumbar fusion is designed to eliminate the instability of the affected vertebral region, thus decreasing low back pain. Unfortunately, fusion is associated with elimination of motion at the index level thus leading to complications that intensify the stresses at adjacent levels resulting in loss of disc height, collapse, abnormal seg- 
ment motion and degeneration. Total disc replacement surgery has emerged as a way to preserve motion of the affected segment and to potentially decrease the incidence of adjacent disc degeneration. ${ }^{2,3}$ Previous clinical studies of lumbar artificial discs have shown at least non-inferiority to lumbar fusion at 2 years post-op in clinical and radiographic outcomes. ${ }^{4-7}$ However, more recent publications have indicated sustained clinical and radiographic outcomes at 5 years in addition to re-analysis of original 2 year data resulting in possible clinical superiority to fusion for some clinical outcomes. ${ }^{8,9}$ The relative merits of single- vs. multiple-level arthroplasty are not well understood; some investigators have reported inferior outcomes with multiple level TDR, while others report no difference between single and multiple level interventions. ${ }^{10-14}$ To date, however, these reports have focused on articulating-design prostheses.

The M6-L Artificial Lumbar Disc System (Spinal Kinetics, Inc., Sunnyvale, CA) is an advanced generation intervertebral disc designed to maintain motion of a functional spinal unit by replicating anatomic, physiologic and biomechanical characteristics of the native disc. The device is comprised of an assembly of high-tensile strength, ultra-high-molecular-weight polyethylene (UHMWPE) fibers wound in multiple redundant layers around a polycarbonate urethane polymer (PCU) core and through titanium alloy endplates. The polymer core is designed to simulate the structure of the nucleus and the fibers are designed to simulate the annulus. This unique design provides a progressive resistance to motion and enables the device to have all six degrees of freedom. The disc also has a polycarbonate urethane polymer sheath surrounding the core and fiber construct to minimize tissue ingrowth as well as the migration of wear debris. Serrated keels located on the exterior surfaces of the device provide acute fixation to the superior and inferior vertebral bodies. Both the endplates and keels are coated with porous titanium to increase bone contact surface area and promote osseointegration (Figure 1). The device is intended to replace the degenerative disc, restore and maintain normal segmental motion without affecting adjacent segments, and achieve a good clinical outcome. The purpose of this study is to examine the clinical and radiographic outcomes of single-level and multiple-level M6-L procedures after 24 months.

\section{Materials and Methods}

This is an ongoing multi-center, single arm, prospective post-market registry. Consecutive patients presenting for surgery with lumbar degenerative disc disease, who gave consent to participate, were enrolled. The Investigators were instructed to select patients according to the Instructions for Use (IFU) and perform the surgery according to the Surgical Technique Manual. The key inclusion/exclusion criteria are presented in Table 1.

This study presents data obtained from all patients who have completed the 24 month follow-up visit by October 2014.

Patient history, neurological examination specific to low back pain including the Oswestry Disability In$\operatorname{dex}^{15,16}(\mathrm{ODI})$ questionnaire and the back and leg pain

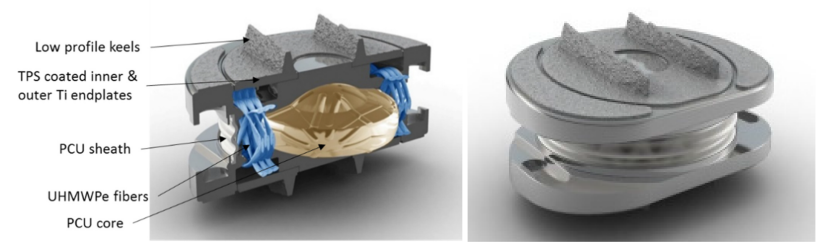

Fig. 1. M6-L Components \& Finished Device.

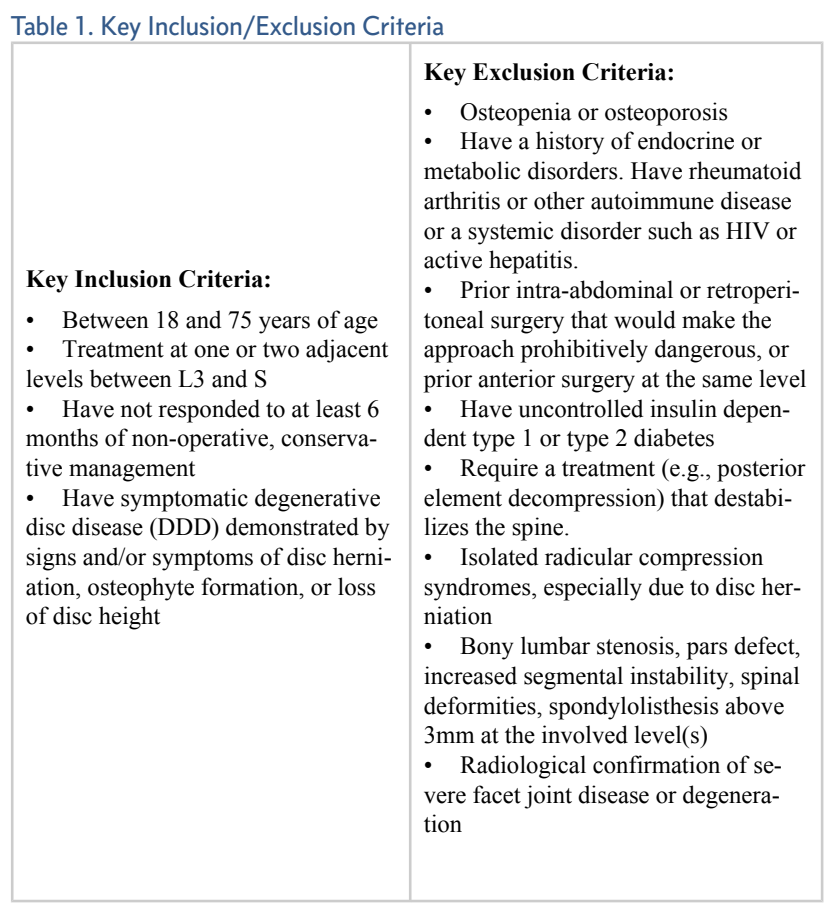


Visual Analogue Scales ${ }^{17}$ (VAS) were collected and evaluated. Patient satisfaction and survivorship were also evaluated. This paper reports on those patients who have completed at least twenty-four months of follow-up to date (October 2014). Additional longterm follow-up will continue.

The Oswestry Disability Index (ODI) is one of the most commonly used outcome measures for spinal disabilities. ${ }^{15,16}$ It is designed to give information as to how back pain has affected patient's ability to manage everyday life. It consists of 10 different categories ranging from pain intensity and personal care to walking, lifting and standing. Each of these categories has a total of five possible answers; the higher the score, the higher the disability. The ODI has been subjected to numerous reviews and still remains a valid measure of various spine-related disabilities. ${ }^{15}$ Because the questionnaire is self-administered and lacks any open-ended questions, it safeguards against any interviewer bias thus leading to reliability and uniformity of presentation. ${ }^{16}$

The Visual Analogue Scale (VAS) is a measurement instrument consisting of a $10 \mathrm{~cm}$ continuous line anchored on one end with "no pain" and on the other end with "worst pain ever." ${ }^{17}$ Patients can indicate their response by placing a vertical mark on the continuous scale designating their pain level. For the purpose of this study the VAS was used to measure back and leg pain. Scores are reported out of 10 possible points. A high score indicates higher pain intensity. A major advantage of VAS is its ratio scale properties which allows for easy comparison between percentage differences in various points in time. ${ }^{17}$

Neutral anteroposterior (AP), neutral lateral, and flexion/extension $(F / E) x$-rays were required per the study protocol, and were utilized to determine extent of disease related to the inclusion/exclusion criteria for the study as defined in the Instructions for Use and Surgical Technique Manuals. In an effort to minimize patient radiation exposure, and in accordance with local practice, the investigators were permitted to bypass some $x$-rays if it was outside of their standard of care x-ray protocol. Radiographic outcomes were assessed by a core laboratory (Medical Metrics, Inc., Houston, TX). Flexion/Extension x-ray images were used to derive global and index level Range of Motion (ROM) in degrees. Disc angles were determined from the neutral lateral images.

\section{Surgical Technique}

Implantation was accomplished through an anterior transperitoneal or retroperitoneal abdominal approach. In this technique, following the approach and identification of the target disc space, the midline is determined and marked. A complete discectomy is performed and the disc space prepared by removal of cartilaginous material, preserving the bony endplates. Posterior mobilization and restoration of posterior height is accomplished with an intervertebral distractor. The endplate size is determined. A Trial Implant of appropriate footprint, posterior height and lordosis angle is inserted into the disc space under close fluoroscopic control and referenced to the midline marker. Upon fluoroscopic verification of correct Trial Implant location, Chisels are used to create keel tracks into the superior and inferior endplates while the Trial remains as a guide. The Trial and Chisels are removed and the artificial disc is implanted using an Implant Inserter under fluoroscopic visualization.

\section{Statistical Methods}

Clinical statistical analyses were performed utilizing a commercially available statistical software program (Sigma Stat v.2.03, SPSS Inc., Chicago, IL) and were based on all available data for all patients who had completed 24 month visits as of October 2014. The data were divided into two subgroups (single-level (SL) and multiple-level (ML) patients) and the outcomes were analyzed for the subgroups individually, the combined dataset, or both, as relevant. Descriptive statistics (mean and standard deviation) were employed to characterize results for continuous variables and their differences. Categorical variables were reported with frequencies or percentages as appropriate. Between-group comparisons were assessed with a t-test, or, if the data were non-normal or categorical, with a Mann-Whitney Rank Sum Test. Longitudinal changes between pre-operative and 24-month visits in the clinical outcome variables were calculated and statistical significance values ( $p$ value) were determined using a paired t-test or, if categorical, with a McNemar's test. Radiographic statis- 
tical analyses were performed using a t-test, MannWhitney Rank Sum Test, or ANOVA as appropriate.

To further evaluate the effectiveness of the surgery, the minimum clinically important difference or the smallest differences that the patient considers beneficial for both ODI and back pain VAS were determined. ${ }^{18,19}$ Patient satisfaction was assessed by a brief survey. Complications were evaluated at each follow up visit and recorded. Adverse events related to device safety which may require additional surgical intervention were recorded. Success was assessed using a composite measure defined as (i) increase in function reflected by a 10 percent point decrease in ODI; (ii) decrease of back pain VAS by $1.8 \mathrm{~cm}$; (iii) no complications, defined as re-operations, revisions, device removals or device-related serious adverse events.

\section{Results}

Eighty three patients had completed their 24 month follow-up visits by October 2014. There were 35 males and 48 females with a mean age of 42.1 years. The mean height and weight were $172.0 \mathrm{~cm}$ and 76.5 $\mathrm{kg}$, respectively. Average BMI for the study patients was 25.7. There were no significant differences in these variables between the SL and ML subgroups ( $p$ $>0.05)$. See Table 2. A total of 121 discs were implanted in the 83 patients: forty-nine (49) patients were treated at 1 level, and 34 at multiple levels, between L2 and S1 (Table 3). As would be expected, the average surgery time was shorter for the single level cases relative to the multiple level cases: the surgery took $79.4 \pm 30.6$ minutes for single level (SL) cases and $127.5 \pm 52.9$ for multiple level (ML) cases. Similarly, blood loss during surgery was $180.8 \mathrm{cc}$ (median $105 \mathrm{cc}$ ) for the SL group and $359.4 \mathrm{cc}$ (median $245 \mathrm{cc}$ ) for the ML group. The overall mean hospital stay duration was 5.7 days (median 6.0) and 6.3 days (median 6.0) for the SL and ML groups, respectively, which is longer than one might expect to see in some markets, but is consistent with standard local healthcare practices at the investigative sites participating in this study.

\section{Clinical Outcomes}

Paired ODI data (patients reporting ODI at both baseline and 24 months) was available for 80 patients (47 SL, $33 \mathrm{ML}$ ). The mean ODI of the combined cohort was $43 \pm 18 \%$ at baseline, and had improved to $21 \pm 19 \%$ at 24 months. Similarly, the SL group, which reported a mean score of $46 \pm 16 \%$, improved to $25 \pm 21 \%$ at 24 months, and the ML group had an ODI score of $37 \pm 19 \%$ at baseline, improving to $16 \pm$ $16 \%$ at 24 months. The results of the paired t-tests indicated that both groups, as well as the overall cohort, were significantly improved at 24 months relative to baseline ( $\mathrm{p}<0.001$, Figure 2$)$. While there was a statistically significant difference between the

\begin{tabular}{|c|c|c|c|}
\hline & $\begin{array}{l}\text { All pa- } \\
\text { tients }\end{array}$ & $\begin{array}{l}\text { Single } \\
\text { Level }\end{array}$ & $\begin{array}{r}\text { Multiple Lev- } \\
\text { els }\end{array}$ \\
\hline Gender: Female & $48(58 \%)$ & $31(63 \%)$ & $17(50 \%)$ \\
\hline Male & $35(42 \%)$ & $18(37 \%)$ & $17(50 \%)$ \\
\hline Age in years $($ Mean \pm SD) & $42.1 \pm 8.2$ & $43.6 \pm 7.5$ & $40.1 \pm 8.8$ \\
\hline Height in $\mathbf{~ c m}($ Mean $\pm \mathrm{SD})$ & $\begin{array}{r}172.0 \pm \\
9.6\end{array}$ & $171.0 \pm 9.4$ & $173.3 \pm 9.9$ \\
\hline Weight in $\mathbf{k g}($ Mean $\pm \mathrm{SD})$ & $\begin{array}{r}76.5 \pm \\
17.4\end{array}$ & $76.2 \pm 17.7$ & $77.0 \pm 17.1$ \\
\hline BMI $($ Mean \pm SD $)$ & $25.7 \pm 4.5$ & $25.9 \pm 4 . .6$ & $25.4 \pm 4.4$ \\
\hline $\begin{array}{l}\text { Surgery Time in min (Mean } \pm \\
\text { SD) }\end{array}$ & & $79.4 \pm 30.6$ & $127.5 \pm 52.9$ \\
\hline Blood loss (cc) (Mean) & & 180.3 & 359.4 \\
\hline $\begin{array}{l}\text { Mean Hospital Stay in days } \\
\text { (Mean) }\end{array}$ & & 5.7 & $6.4(6.0)$ \\
\hline
\end{tabular}

Note: Age, height, weight, BMI and surgery time were available for $98 \%$ of patients. Blood loss and hospital stay were available for $89 \%$ of patients.

\begin{tabular}{|c|c|}
\hline & All patients \\
\hline Index Level(s) & n (\%) of pts \\
\hline $\mathrm{L} 4 / \mathrm{L} 5$ & $12(14.5 \%)$ \\
\hline $\mathrm{L} 5 / \mathrm{S} 1$ & $37(44.6 \%)$ \\
\hline $\mathrm{L} 2 / \mathrm{L} 3 ; \mathrm{L} 3 / \mathrm{L}^{*}$ & $1(1.2 \%)$ \\
\hline L3/L4; L4/L5 & $5(6.0 \%)$ \\
\hline $\mathrm{L} 3 / \mathrm{L} 4 ; \mathrm{L} 5 / \mathrm{S} 1$ & $1(1.2 \%)$ \\
\hline L4/L5; L5/S1 & $23(27.7 \%)$ \\
\hline L3/L4; L4/L5; L5/S1* & $4(4.8 \%)$ \\
\hline \multicolumn{2}{|c|}{$\begin{array}{l}\text { * Although the IFU for the M6-L device indicates implantation of the device } \\
\text { at } 1 \text { or } 2 \text { levels from L3 - S1, the decision to implant the device at } L 2 / 3 \text { was } \\
\text { made for } 1 \text { patient and the decision to implant at } 3 \text { levels was made for } 4 \\
\text { patients. }\end{array}$} \\
\hline
\end{tabular}


SL and ML groups both at baseline and at 24 months $(\mathrm{p}<0.05)$, each subgroup experienced an average decrease of 21 percentage points in ODI from its respective baseline, resulting in a nonsignificant difference in this measure between the two groups ( $p$ > $0.05)$.

According to the literature, a 10-point improvement in ODI is considered the minimum clinically important difference (MCID). ${ }^{19}$ In this study, $71 \%$ of the responding patient cohort (72\% of SL patients, and 70\% of ML patients) achieved MCID at 24 months.

According to ODI criteria, 94\% $(\mathrm{n}=44)$ and $85 \%$ $(\mathrm{n}=28)$ of the single level and multi-level groups, respectively, and $90 \%(\mathrm{n}=72)$ of the total study population, had a disability of moderate to bed-bound preoperatively, with only $6 \%, 15 \%$ and $10 \%$, respectively, reporting minimal disability at baseline. At the 24-month follow-up, disability was significantly improved relative to baseline, with $51 \%(\mathrm{n}=24)$ of the SL patients and $73 \%(\mathrm{n}=24)$ of the ML patients reporting minimal disability $(\mathrm{p}<0.001)$. The level of patient disability pre-operatively and at 24 months is shown in Figure 3 and Figure 4 for the SL and ML groups.

Back pain was $6.2 \pm 2.3$ and $6.6 \pm 2.0$ pre-operatively on the visual analogue scale for the SL and ML groups, respectively; the combined cohort (totaling 79 patients, $46 \mathrm{SL}$ and $33 \mathrm{ML}$, with available VAS data at both timepoints) had a VAS back pain score 6.4 \pm 2.2 . At 24 months follow-up, mean back pain VAS decreased significantly for the SL, ML, and

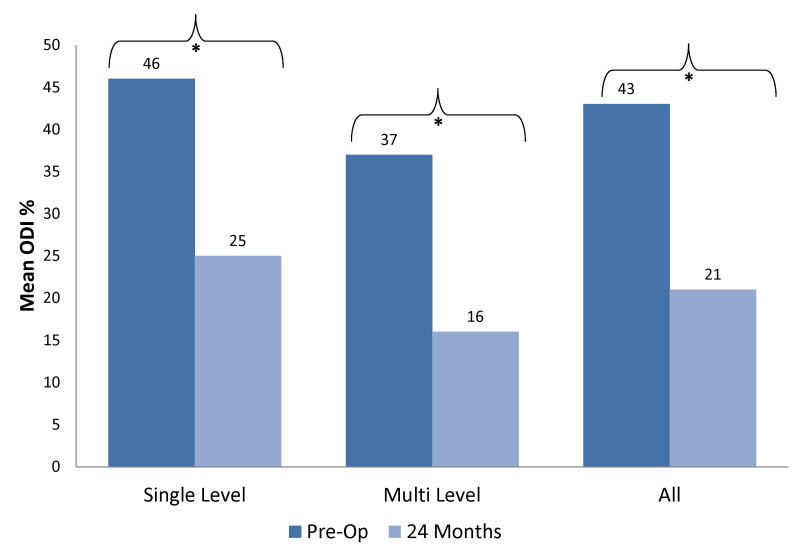

Fig. 2. Mean Oswestry Disability Index. ${ }^{*} p<0.001$. There was a significant difference between the SL and ML groups at both Pre-Op and 24 months $(p<0.05)$ combined cohorts relative to their respective baseline values $(\mathrm{p}<0.001$; Figure 5$)$. Mean pre-operative VAS leg pain was $3.2 \pm 2.1$ for the combined dataset; the SL and ML scores were similar to the combined dataset $(3.2 \pm 1.9$ for the SL group and 3.2 \pm 2.3 for the ML group). A similar pattern of significant decrease was observed in the leg pain VAS data for all cohorts at 24 months (SL 1.9 $\pm 22, \mathrm{ML} 1.9 \pm 2.0$, Combined $1.6 \pm 2.1 ; \mathrm{p}<0.001)$. There were no statistically significant differences between the SL and ML groups in either the pre-op or the 24 month cohorts for either of the VAS measures $(\mathrm{p}>0.05)$.

It has been reported that an improvement of 1.8-1.9 $\mathrm{cm}$ in VAS back pain can be equivalent to the minimum clinically important difference. ${ }^{19}$ In this cohort, $68 \%$ of the patients $(65 \% \mathrm{SL}, 73 \% \mathrm{ML})$ achieved MCID based on $1.8 \mathrm{~cm}$ improvement in back pain VAS.

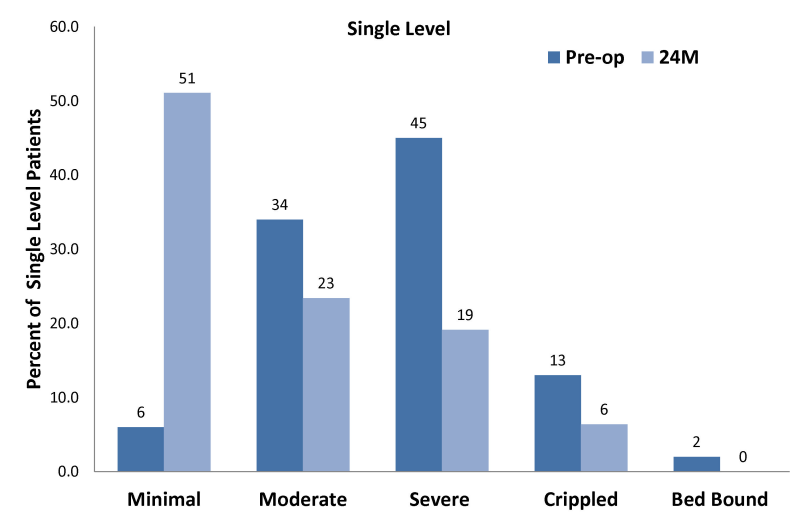

Fig. 3. Disability Level at baseline and 24 Months for the Single Level patients.

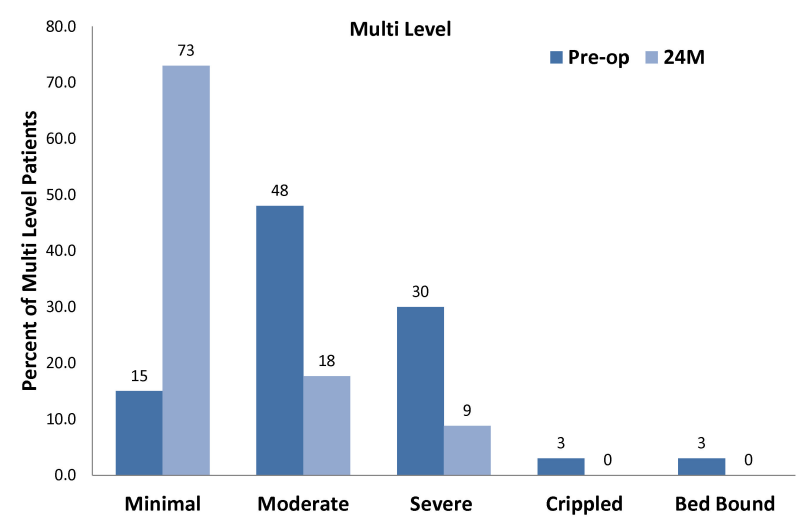

Fig. 4. Disability Level at baseline and 24 Months for the Multi-Level Patients. 
Seventy three percent of patients (78\% of the SL cohort and $68 \%$ of the ML cohort) completed at least one question of a two-question patient satisfaction survey. $68 \%$ of responding single level patients and $87 \%$ of responding patients in the ML group indicated that their condition was greatly improved (75\% overall), while and $92 \%$ and $95 \%$ of responding single level and multiple level patients, respectively, reported willingness to undergo surgery again under the same circumstances. There were no statistically significant differences between the two groups on either question $(\mathrm{p}>0.05)$.

\section{Radiographic Outcomes}

Radiographic outcomes were derived from 24 month data on disc angle, index level range of motion and global range of motion analysis. Forty-six of the single-level study participants and 33 of the multilevel study participants (totaling 116 implanted levels in the combined SL + ML group) completed the neutral radiographs required to assess disc angle; 47 single-level and 33 multi-level patients (totaling 117 implanted levels in the combined group) completed the flexion/extension radiographs required to assess global and index range of motion, respectively.

Figure 6 and Figure 7 show a comparison of pre and post-operative lateral $\mathrm{x}$-rays over time for a single level disc replacement at L5/S1 and a two-level disc replacement at L4/L5 and L5/S1.

A comparison of the single level vs. multi-level disc angles at 24 months indicated that the disc angles of

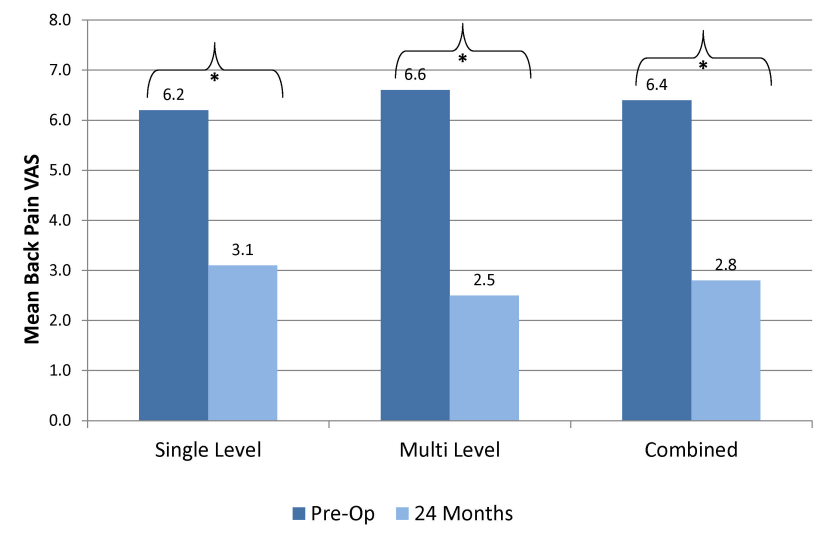

Fig. 5. Back Pain VAS at Baseline and 24 Months for the Single Level (SL), Multi Level (ML), and Combined (C) datasets. ${ }^{*} p<0.001$. There was no significant difference between the two cohorts at either pre-op or 24 months. the single level cases were significantly larger than those of the multi-level group $\left(19.0 \pm 5.0^{\circ} \mathrm{vs}\right.$ $\left.14.6 \pm 5.3^{\circ} ; \mathrm{p}<0.001\right)$. This statistically significant difference was not due to differences in index level: an ANOVA analysis performed taking into account index level (using the subset of 105 samples implanted at L4-L5 or L5-S1) indicated a statistically significant difference with single level vs. multiple level cases $(p<0.001$, Figure 8$)$ but no difference in angle between index levels after taking differences in SL vs $\mathrm{ML}$ into account $(\mathrm{p}=0.903)$.

By contrast, the index level flexion/extension (F/E) range of motion (ROM) data were not significantly different between the SL and ML groups $\left(5.0 \pm 3.6^{\circ}\right.$ for the SL group, $5.9 \pm 4.2^{\circ}$ for the ML group; $p>$ 0.05). Finally, global range of motion was not significantly different between the SL and ML groups at 24 months $\left(40.6 \pm 13.4^{\circ}\right.$ for the SL group vs. $39.4 \pm$ $13.0^{\circ}$ for the ML group; $\left.\mathrm{p}>0.05\right)$.

\section{Clinical Success and Patient Safety}

As indicated previously, individual patient success was assessed using a composite measure encompass-

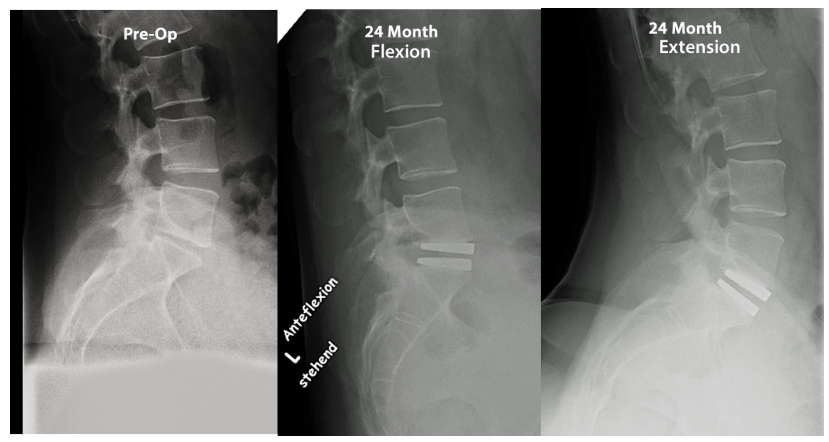

Fig. 6. Lateral radiographs of the lumbar spine including the index level, for single level disc replacement at L5/S1.

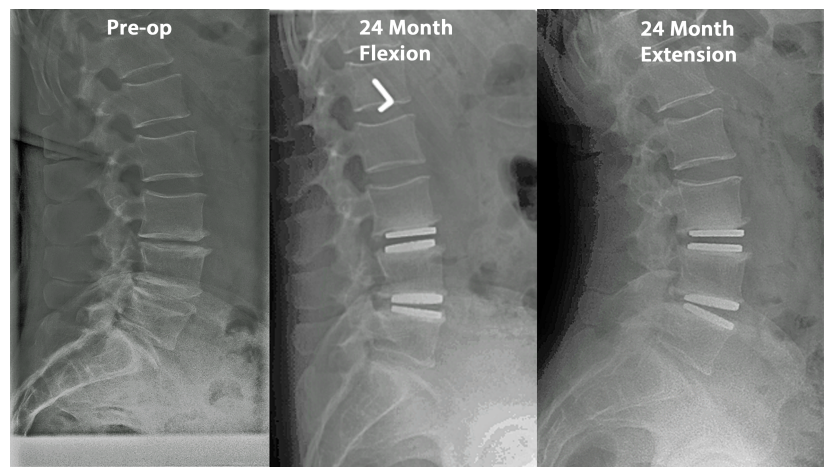

Fig. 7. Lateral radiographs of the lumbar spine including the index level, for two level disc replacement at L4/L5 and L5/S1. 
ing changes in ODI and VAS and lack of relevant complications. According to the composite measure for success, at 24 months overall clinical success was attained for $61 \%$ of the SL patients and $64 \%$ of the ML patients (62\% overall). Five patients reported complications that were considered to be mild neurological deficits that persisted at 24 months; an additional patient reported a more severe neurological condition (suspected cauda equina syndrome) which resolved at the next followup. There were no enrolled subjects converted to fusion either pre or intraoperatively. There were no reported revisions, device removals or device-related serious adverse events, nor were there any other reported unanticipated or serious adverse device effects.

\section{Discussion}

Low back pain is one of the most prevalent problems in industrialized countries and often results in decline in the quality of life of the affected individuals. There are a number of contributors to low back pain, one of which is degenerative disc disease of the spine. ${ }^{20}$ Although fusion has been well accepted for the treatment of DDD, high rates of complications and stress to adjacent segments remain a major concern. It has been reported that up to $20 \%$ of fusion patients have required surgery at an adjacent level. ${ }^{21}$ This increased risk associated with fusion led to a paradigm shift towards innovative technologies that aim to preserve motion and reduce adjacent level disc degeneration. ${ }^{13,21}$ Lumbar total disc replacement (TDR) is one such technology that has since become more popular as an alternative to fusion. Artificial

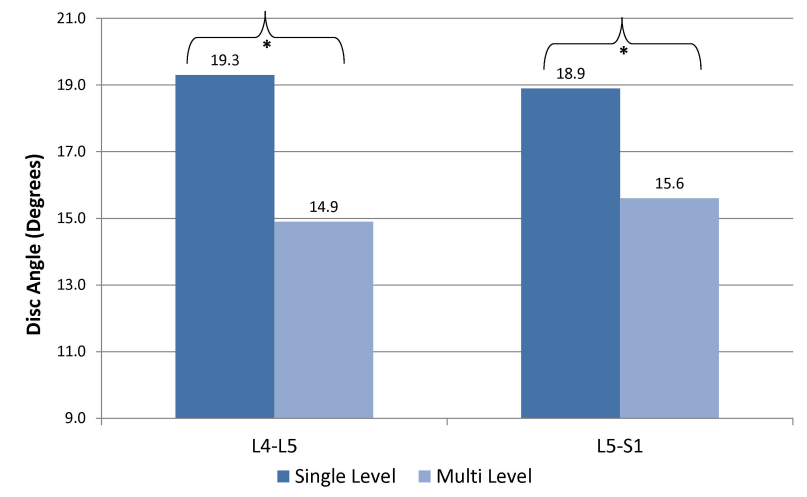

Fig. 8. Disc Angle for the single level and multi-level cases at L4-L5 and L5-S1. * $p<0.05$. disc replacement devices were developed with a goal of preserving motion and avoiding various fusion-related complications. ${ }^{3}$ The compressible core device studied herein is intended to further mimic the natural function of the lumbar disc in an attempt to better preserve the kinematics and biomechanics of the affected spinal segment.

While the results of TDR have been previously reported for several different arthroplasty designs, this is the first study to report clinical and radiographic outcomes of TDR with the M6-L in single level vs multiple level implantations with two years of followup. The results demonstrated that both the single level and multiple level cohorts experienced significant improvement at 24 months. The ODI and VAS scores for both the SL and ML groups improved significantly at 24 months relative to baseline. Relative to single level procedures, multi level procedures demonstrated either comparable results, or results that trended favorably towards the multi-level procedures. ODI improvement was slightly higher in the ML group (57\%, vs. $46 \%$ for the SL cohort), and a higher percentage of the ML group reported minimal disability at 24 months (73\% vs $51 \%$ ). A similar trend was observed in the VAS scores. While a comparable percentage of patients achieved ODI MCID at 24 months, there was a trend towards a greater percentage of patients in the ML group achieving VAS MCID at 24 months relative to the SL group. The results of the patient survey demonstrated a trend towards increased patient satisfaction in the ML group relative to the SL group, but comparable willingness to undergo the same surgery again. The composite measure of success was also comparable between the two groups. The radiographic analysis indicated comparable results for the SL and ML groups in flexion/extension ROM and global ROM, but demonstrated differences in disc angles between the two groups.

The overall clinical results of the present study are consistent with the other studies of 1-level and 2-level TDRs. Several authors have reported ODI scores for single-level TDR procedures performed using the ProDisc-L, Charité, and Maverick prostheses and have found improvement from baseline ranging from 38-63\%.$^{3-5,79-12,14,22-24}$ ODI improvement rang- 
ing from 28\%-68\% has likewise been reported after multi-level TDR. ${ }^{10-12,14,25,26}$ The order of magnitude of the observed changes in VAS at 24 months in the present study is also comparable with that reported in the literature, where improvement in VAS is reported in the range of $47-75 \%$ in 1-level cases. . $3,5,79-12,14,22-24_{\text {and }} 37-75 \%$ in 2-level cases ${ }^{10-12,14,25,26}$

Comparisons between single-level and multi-level cohorts in the literature present mixed results. The results of the present study are consistent with Yue et al. ${ }^{14}$ The authors compared 25 monosegmental and 21 bisegmental ProDisc-L implantations and found no statistically significant differences in clinical or radiographic outcomes between the 1-level and 2-level cases. Similar to the present study, they also observed trends towards better clinical outcomes in the 2-level patients, although these differences were not statistically significant. On the other hand, Di Silvestre et al. ${ }^{10}$ examined the clinical and radiographic outcomes of 16 single-level and 16 two-level Charité implantations. Although they found no statistically significant difference in clinical or radiographic outcomes at three years, the authors were less optimistic about multiple level TDR: they cautioned that there were more complications in the bi-segmental group and that the monosegmental group presented with both better scores and a higher level of patient satisfaction. Similarly, Hannibal et al. ${ }^{11}$ analyzed 25 single level and 29 two-level cases and found no statistically significant differences between the two groups, however they noted trends towards worse outcomes for the two-level cases. Bertagnoli et al. published two adjacent papers, one on single level and one on multi-level cases, but did not perform a comparison of the two cohorts. ${ }^{22,25}$ Based on the data presented by the authors, however, a trend towards increased improvement in ODI and VAS in the multi-level cohort relative to the single-level cohort can be observed. Our results stand in contrast to those reported by Siepe et al. ${ }^{12}$ who reported the outcomes of 79 1-level and 20 multi-level patients implanted with the ProDisc-L. The authors found that ODI, VAS, and patient satisfaction were worse in patients implanted at two levels relative to those implanted at one level. They concluded that pain from the iliosacral joint or facet joints was responsible for the diminished outcomes; they also noted that increased segmental in- stability has been a concern in multisegmental procedures.

There are several factors which may explain the inconsistencies in the results between the above-referenced studies and the results presented in the present study. Some variation may be due to differences between investigational sites and inclusion and exclusion criteria. Small and/or imbalanced cohort sizes may also play a role. Additionally, the inherent variability in the patient population, and the resulting large standard deviations, may explain why trends were not found to be statistically significant. Another factor to consider is the initial difference in ODI (but not VAS) between the two cohorts in the present study. Although the decrease in ODI was the same between the two cohorts, it is possible that some difference between the two groups pre-operatively is responsible for the similarity of outcomes between the two groups at 24 months.

A direct comparison of the results of the previous studies to the present study may also be confounded by differences in the technologies themselves, which may lead to biomechanical differences in vivo, particularly when multiple levels are involved. Segmental instability has been implicated in poorer outcomes of multi-segment procedures using articulating prostheses, ${ }^{12,27}$ and changes in the balance of load and shear between the anterior and posterior columns are also hypothesized to be related to clinical outcome. ${ }^{28,29}$ Articulating TDRs are designed to move with minimal resistance over their ranges of motion, while the M6- $\mathrm{L}$ is a compressible-core disc, unconstrained in IAR location, which is designed to progressively resist movement over its range of motion in all axes. Separate biomechanical investigations of an articulating disc and of the M6-L have been performed which, upon comparison, demonstrate a difference in the load-displacement behavior of the different designs. O'Leary et al. ${ }^{30}$ studied the biomechanical behavior of the Charite TDR and noted that the pattern of the load-displacement curve of the articulating TDR varied from an intact disc in that it displayed regions of both relatively small and relatively large changes in angle with gradual moment application, while Patwardhan et al. ${ }^{31}$ demonstrated that the pattern of the M6-L approximated intact controls. As a 
result of the design and biomechanical differences between the M6-L and articulating discs, the propensity for segmental instability and the relationship between the TDR and the native adjacent structures, including the iliosacral joint and facet joints, is likely to be different in the M6-L, perhaps leading to improved outcomes in multi-level cases.

The radiographic outcomes of the present study demonstrated that the index level ROM were not significantly different between the single-level and multi-level cohorts, but that there was a significant difference in the disc angle between the two cohorts, even after taking into account potential differences in index level. Reports from the literature reflect a lack of consistency in the ROM achieved at the index level after TDR with a variety of articulating prostheses, ${ }^{5,32-36}$ however the similarity of the index level ROMs between the two cohorts in the present study was consistent with the results reported by other investigators. ${ }^{10,14,22,25}$ The statistically significant change in disc angle between the two cohorts observed herein merits further study. It is possible that the smaller disc angles in the multi-segmental group is indicative of an adaptability of the M6-L to sagittal balance requirements, however an analysis of sagittal balance on the two cohorts is not possible from the available radiographs.

This study reports results from eighty-three patients followed in a post-market registry. Despite the limitations imposed by the sample size and study type, a registry is an effective tool that allows for data to be collected on patients treated according to standard of care and demonstrates the results of the treatment in a real-life setting. The data from the registry indicate that the compressible core device behavior and results are promising and are consistent with that observed in other TDRs.

\section{Conclusion}

The purpose of a TDR is to provide clinical relief of symptoms and improved, physiologic range of motion, disc angle and sagittal balance, which in turn may lead to less wear and stress on adjacent vertebral levels and have a positive effect on clinical outcomes. The improvements in outcomes reported in this reg- istry study, such as disability, pain relief, patient satisfaction, and lack of serious adverse events, suggest that the compressible core device behaves as intended, with an adequate initial safety and effectiveness profile at the two year timepoint for both single and multi-level procedures. As in the case of other lumbar artificial discs, a larger sample size and extended follow-up are necessary; the post-market registry continues for this purpose.

\section{References}

1. Deyo RA. Low-back pain. Sci Am. Aug 1998;279(2):48-53.

2. Canbulat N, Sasani M, Ataker Y, et al. A rehabilitation protocol for patients with lumbar degenerative disk disease treated with lumbar total disk replacement. Arch Phys Med Rehabil. Apr 2011;92(4):670-676.

3. Blondel B, Tropiano P, Gaudart J, Marnay T. Clinical results of total lumbar disc replacement regarding various aetiologies of the disc degeneration: a study with a 2-year minimal follow-up. Spine (Phila Pa 1976). Mar 1 2011;36(5):E313-319.

4. Blumenthal S, McAfee PC, Guyer RD, et al. A prospective, randomized, multicenter Food and Drug Administration investigational device exemptions study of lumbar total disc replacement with the CHARITE artificial disc versus lumbar fusion: part I: evaluation of clinical outcomes. Spine. Jul 15 2005;30(14):1565-1575; discussion E1387-1591.

5. Gornet MF, Burkus JK, Dryer RF, Peloza JH. Lumbar disc arthroplasty with Maverick disc versus stand-alone interbody fusion: a prospective, randomized, controlled, multicenter investigational device exemption trial. Spine (Phila Pa 1976). Dec 1 2011;36(25):E1600-1611.

6. Sasso RC, Foulk DM, Hahn M. Prospective, randomized trial of metal-on-metal artificial lumbar disc replacement: initial results for treatment of discogenic pain. Spine (Phila Pa 1976). Jan 15 2008;33(2):123-131.

7. Zigler J, Delamarter R, Spivak JM, et al. Results of the prospective, randomized, multicenter Food and Drug Administration investigational device exemption study of the ProDisc-L total disc replacement versus circumferential fusion for the treatment 
of 1-level degenerative disc disease. Spine. May 15 2007;32(11):1155-1162; discussion 1163.

8. Geisler FH. Surgical Treatment for Discogenic Low-Back Pain: Lumbar Arthroplasty Results in Superior Pain Reduction and Disability Level Improvement Compared With Lumbar Fusion. SAS Journal. 2007;1(1):12-19.

9. Guyer RD, McAfee PC, Banco RJ, et al. Prospective, randomized, multicenter Food and Drug Administration investigational device exemption study of lumbar total disc replacement with the CHARITE artificial disc versus lumbar fusion: five-year followup. Spine J. May 2009;9(5):374-386.

10. Di Silvestre M, Bakaloudis G, Lolli F, Vommaro F, Parisini P. Two-level total lumbar disc replacement. Eur Spine J. Jun 2009;18 Suppl 1:64-70. 11. Hannibal M, Thomas DJ, Low J, Hsu KY, Zucherman J. ProDisc-L total disc replacement: a comparison of 1-level versus 2-level arthroplasty patients with a minimum 2-year follow-up. Spine (Phila Pa 1976). Oct 1 2007;32(21):2322-2326.

12. Siepe CJ, Mayer HM, Heinz-Leisenheimer M, Korge A. Total lumbar disc replacement: different results for different levels. Spine (Phila Pa 1976). Apr 1 2007;32(7):782-790.

13. Siepe CJ, Mayer HM, Wiechert K, Korge A. Clinical results of total lumbar disc replacement with ProDisc II: three-year results for different indications. Spine (Phila Pa 1976). Aug 1 2006;31(17):1923-1932.

14. Yue J, Zhang K, Bai HX, et al. A comparison of patients who have undergone 1-Level versus 2-Level ProDisc arthroplasty: a prospective study with minimum of 5-year follow-up. Spine (Phila Pa 1976). Jun 15 2013;38(14):1194-1198.

15. Fairbank JC, Couper J, Davies JB, O'Brien JP. The Oswestry low back pain disability questionnaire. Physiotherapy. Aug 1980;66(8):271-273.

16. Fairbank JC, Pynsent PB. The Oswestry Disability Index. Spine (Phila Pa 1976). Nov 15 2000;25(22):2940-2952; discussion 2952.

17. Katz J, Melzack R. Measurement of pain. The Surgical clinics of North America. Apr 1999;79(2):231-252.

18. Copay AG, Glassman SD, Subach BR, Berven S, Schuler TC, Carreon LY. Minimum clinically important difference in lumbar spine surgery patients: a choice of methods using the Oswestry Disability Index, Medical Outcomes Study questionnaire Short Form 36, and pain scales. Spine J. Nov-Dec 2008;8(6):968-974.

19. Hagg O, Fritzell P, Nordwall A. The clinical importance of changes in outcome scores after treatment for chronic low back pain. Eur Spine J. Feb 2003;12(1):12-20.

20. Policy Statement on Lumbar Spinal Fusion

Surgery: International Society for the Advancement of Spine Surgery (ISASS); 2011-07-15 2011.

21. Wilson-MacDonald J, Boeree N. Controversial topics in surgery: degenerative disc disease: disc replacement. For. Annals of the Royal College of Surgeons of England. Jan 2007;89(1):6-11.

22. Bertagnoli R, Yue JJ, Shah RV, et al. The treatment of disabling single-level lumbar discogenic low back pain with total disc arthroplasty utilizing the Prodisc prosthesis: a prospective study with 2-year minimum follow-up. Spine (Phila Pa 1976). Oct 1 2005;30(19):2230-2236.

23. Guyer RD, Thongtrangan I, Ohnmeiss DD. Outcomes of CHARITE Lumbar Artificial Disk versus Fusion: 5-Year Data. Seminars in Spine Surgery. 2012;24(1):32-36.

24. Zigler JE, Delamarter RB. Five-year results of the prospective, randomized, multicenter, Food and Drug Administration investigational device exemption study of the ProDisc-L total disc replacement versus circumferential arthrodesis for the treatment of single-level degenerative disc disease. J Neurosurg Spine. Dec 2012;17(6):493-501.

25. Bertagnoli R, Yue JJ, Shah RV, et al. The treatment of disabling multilevel lumbar discogenic low back pain with total disc arthroplasty utilizing the ProDisc prosthesis: a prospective study with 2-year minimum follow-up. Spine (Phila Pa 1976). Oct 1 2005;30(19):2192-2199.

26. Delamarter R, Zigler JE, Balderston RA, Cammisa FP, Goldstein JA, Spivak JM. Prospective, randomized, multicenter Food and Drug Administration investigational device exemption study of the ProDisc-L total disc replacement compared with circumferential arthrodesis for the treatment of twolevel lumbar degenerative disc disease: results at twenty-four months. J Bone Joint Surg Am. Apr 20 2011;93(8):705-715. 
27. SariAli el H, Lemaire JP, Pascal-Mousselard H, Carrier $\mathrm{H}$, Skalli W. In vivo study of the kinematics in axial rotation of the lumbar spine after total intervertebral disc replacement: long-term results: a 10-14 years follow up evaluation. Eur Spine J. Oct 2006;15(10):1501-1510.

28. Dooris AP, Ares PJ, Gabriel SM, Serhan H. Wear Characterization of an Artificial Disc using ASTM Guidelines. Orthopaedic Research Society2005:1335.

29. Huang RC, Girardi FP, Cammisa FP, Jr., Wright TM. The implications of constraint in lumbar total disc replacement. J Spinal Disord Tech. Aug 2003;16(4):412-417.

30. O'Leary P, Nicolakis M, Lorenz MA, et al. Response of Charite total disc replacement under physiologic loads: prosthesis component motion patterns. Spine J. Nov-Dec 2005;5(6):590-599.

31. Patwardhan A, Voronov LI, Renner SM, Carandang G, Havey RM. Total Disc Arthroplasty Using A Compressible Disc Prosthesis: Effect Of Compressive Preload Magnitude On The Kinematics Of Lumbar Spine. Paper presented at: Ninth Annual Global Symposium on Motion Preservation Technology2009; London, England.

32. Chung SS, Lee CS, Kang CS, Kim SH. The effect of lumbar total disc replacement on the spinopelvic alignment and range of motion of the lumbar spine. J Spinal Disord Tech. Jul 2006;19(5):307-311. 33. Huang RC, Girardi FP, Cammisa FP, Jr., Lim MR, Tropiano P, Marnay T. Correlation between range of motion and outcome after lumbar total disc replacement: 8.6-year follow-up. Spine. Jun 15 2005;30(12):1407-1411.

34. McAfee PC, Cunningham B, Holsapple G, et al. A prospective, randomized, multicenter Food and Drug Administration investigational device exemp- tion study of lumbar total disc replacement with the CHARITE artificial disc versus lumbar fusion: part II: evaluation of radiographic outcomes and correlation of surgical technique accuracy with clinical outcomes. Spine. Jul 15 2005;30(14):1576-1583; discussion E1388-1590.

35. Ross R, Mirza AH, Norris HE, Khatri M. Survival and clinical outcome of SB Charite III disc replacement for back pain. $J$ Bone Joint Surg Br. Jun 2007;89(6):785-789.

36. Siepe CJ, Hitzl W, Meschede P, Sharma AK, Khattab MF, Mayer MH. Interdependence between disc space height, range of motion and clinical outcome in total lumbar disc replacement. Spine (Phila Pa 1976). Apr 20 2009;34(9):904-916.

\section{Disclosures}

Christoph Schätz has received reimbursement for travel expenses from and owns shares in Spinal Kinetics. Lutz Gössel has received reimbursement for travel expenses in Spinal Kinetics. Neither Karsten Ritter-Lang nor Nadine Dreßler report any relevant financial disclosures.

\section{Corresponding Author}

Dr. Med. Christoph Schätz, Orthopädische Klinik Markgröningen gGmbH, Kurt-Lindemann-Weg 10, 71706 Markgröningen, Germany. c.schaetz@okm.de

Published 7 May 2015.

This manuscript is generously published free of charge by ISASS, the International Society for the Advancement of Spine Surgery. Copyright @ 2015 ISASS. To see more or order reprints or permissions, see http://ijssurgery.com. 